\title{
The Current Configuration of the OSTIA System for Operational Production of Foundation Sea Surface Temperature and Ice Concentration Analyses
}

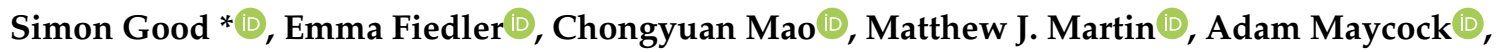

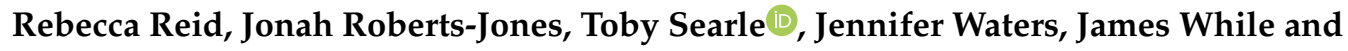 \\ Mark Worsfold \\ Met Office, FitzRoy Road, Exeter, Devon EX1 3PB, UK; emma.fiedler@metoffice.gov.uk (E.F.); \\ chongyuan.mao@metoffice.gov.uk (C.M.); matthew.martin@metoffice.gov.uk (M.J.M.); \\ adam.maycock@metoffice.gov.uk (A.M.); rebecca.reid@metoffice.gov.uk (R.R.); \\ jonah.roberts-jones@metoffice.gov.uk (J.R.-J.); toby.searle@metoffice.gov.uk (T.S.); \\ jennifer.waters@metoffice.gov.uk (J.W.); james.while@metoffice.gov.uk (J.W.); \\ mark.worsfold@metoffice.gov.uk (M.W.) \\ * Correspondence: simon.good@metoffice.gov.uk
}

Received: 24 January 2020; Accepted: 17 February 2020; Published: 21 February 2020

\begin{abstract}
The Operational Sea Surface Temperature and Sea Ice Analysis (OSTIA) system generates global, daily, gap-filled foundation sea surface temperature (SST) fields from satellite data and in situ observations. The SSTs have uncertainty information provided with them and an ice concentration (IC) analysis is also produced. Additionally, a global, hourly diurnal skin SST product is output each day. The system is run in near real time to produce data for use in applications such as numerical weather prediction. Data production is monitored routinely and outputs are available from the Copernicus Marine Environment Monitoring Service (CMEMS; marine.copernicus.eu). As an operational product, the OSTIA system is continuously under development. For example, since the original descriptor paper was published, the underlying data assimilation scheme that is used to generate the foundation SST analyses has been updated. Various publications have described these changes but a full description is not available in a single place. This technical note focuses on the production of the foundation SST and IC analyses by OSTIA and aims to provide a comprehensive description of the current system configuration.
\end{abstract}

Keywords: sea surface temperature; lake surface water temperature; ice concentration; satellite; in situ

\section{Introduction}

The Operational Sea Surface Temperature and Sea Ice Analysis (OSTIA) system was developed at the Met Office (the UK's national meteorological service; https://www.metoffice.gov.uk/) to meet its need for near real time, accurate, global sea surface temperature (SST) data for numerical weather prediction (NWP) [1]. It uses SST observations from in situ observing instruments such as drifting buoys in combination with satellite SST data from a variety of sensors to form daily, globally complete, model-free analyses of foundation SST (the SST from which the diurnal cycle grows) on a $\frac{1}{20}^{\circ}$ grid. SST uncertainty and ice concentration (IC) fields are also produced. Although designed for use in NWP, OSTIA data have found a variety of applications including ocean (e.g., [2]) and atmospheric (e.g., [3]) reanalyses and have been used in numerous scientific studies (e.g., recently [4,5]). Since the OSTIA system was originally set up and documented in [1], a variety of changes have been made. These include creating configurations for generating long-term reprocessed datasets [6-8] and 
extending the OSTIA system to include the generation of diurnal skin SST products [9]. Changes to the near real time foundation SST and IC part of the OSTIA system have been reported individually (see Section 2 for an overview) but a complete description is not available in one place. The aim of this technical note is to provide a summary of the current configuration.

A description of the current system configuration of the OSTIA system for generating the foundation SST and IC products is given in Section 2. This is followed in Section 3 by a description of the outputs. Section 4 discusses the impact of the various changes to the system and Section 5 contains the conclusions.

\section{Methods}

Changes to the foundation SST and IC analysis part of the OSTIA system since its inception have included updates to the input data that are used as the satellite systems have evolved. The processing of the data has also improved. Perhaps the most significant update has been a change to the data assimilation scheme that underpins the system. Data assimilation is commonly associated with combining observations and a forecast field from a numerical model in order to create initial conditions for further predictions. Data assimilation is similarly used to create OSTIA analyses with the exception that the forecast field is provided by damped persistence of the previous day's analysis anomalies rather than taking it from a numerical model. The data assimilation scheme that has previously been used in OSTIA since its inception is the Analysis Correction (AC) scheme [10,11]. This uses an iterative approach to solve the optimal interpolation equation. The new version of the system uses NEMOVAR [12], which is a variational data assimilation scheme that is developed alongside the Nucleus for European Modelling of the Ocean (NEMO) model [13]. This echoes work done to upgrade the Met Office Forecasting Ocean Assimilation Model (FOAM) system to use NEMOVAR [14] and has facilitated various improvements to OSTIA including the introduction of an IC analysis to replace a simple regridding of the input data. Other changes to the OSTIA system have been the introduction of estimates of lake water temperatures and ICs [15], updates to the error covariance estimates that are crucial to the merging of the input data and an increase to the number of iterations of the AC assimilation scheme to converge more closely on the solution [16], and, most recently, an update that improved the resolution of SST features in the analyses [17].

An overview of the current OSTIA processing system is shown in Figure 1. It consists of five main parts, which are each described in detail in the following subsections: observation preprocessing (Section 2.1), IC analysis (Section 2.2), satellite SST bias estimation (Section 2.3), SST analysis (Section 2.4) and postprocessing of the outputs (Section 2.5).

\subsection{Observation Processing}

\subsubsection{Data Sources}

Satellite and in situ SST and satellite IC data are pulled from data disseminators or are received through EUMETCast or World Meteorological Organisation (WMO) Global Telecommunication System (GTS) communication. Input SST data that cover the period from 18:00 UTC on the day prior to the date represented by the analysis to 6:00 UTC on the day after are allowed to be ingested. However, if they were included in the previous analysis they are not reused. The SST data that are currently used are listed in Table 1 . The selection of input data used in OSTIA is continuously under review and new sensors are added if they improve the quality of the OSTIA analyses or are deemed useful to increase resilience of the system to data outages or loss of other sensors. Similarly, sensors will be removed from the system if they fail or their data quality degrades. 


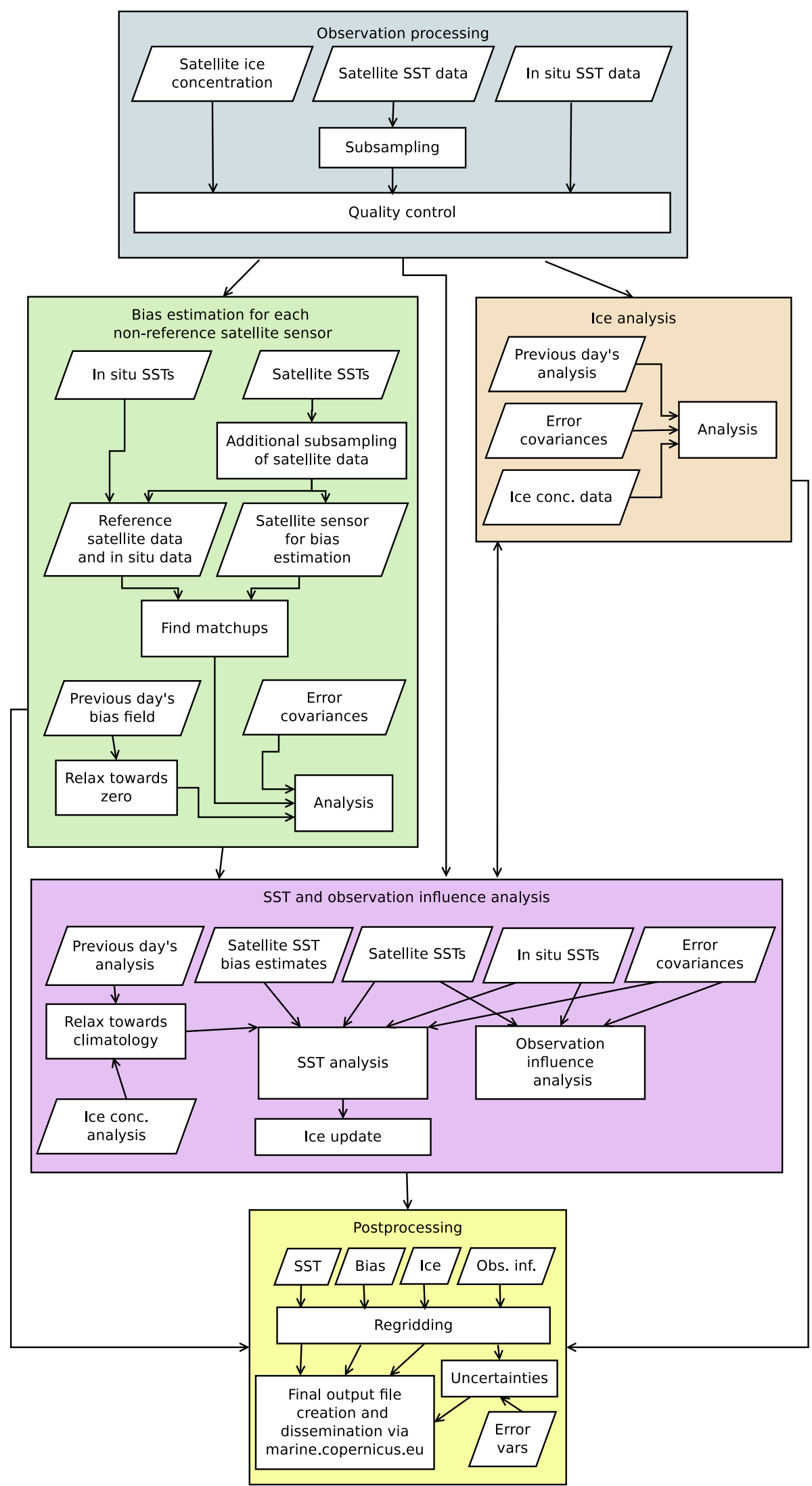

Figure 1. Diagram of the Operational Sea Surface Temperature and Sea Ice Analysis (OSTIA) processing system, showing the principal components of the system and the dependencies between each. 
Table 1. List of input sea surface temperature (SST) data used in OSTIA, including the instrument and the satellite on which it is situated, the data producer, the data level (defined in [18]), spatial resolution (as defined in the file metadata), the level of thinning applied (for example $2 \times 2$ means that 1 in every 2 data values is kept in both dimensions) and citations and notes associated with the data use. Acronyms/abbreviations are defined and acknowledgments for data use are provided at the end of this technical note.

\begin{tabular}{|c|c|c|c|c|c|c|c|}
\hline Instrument & Satellite & Producer & Data Level & Spatial Resolution & Thinning & References & Notes \\
\hline AMSR2 & GCOM-W & REMSS & L2P & $25 \mathrm{~km}$ & $2 \times 2$ & {$[19,20]$} & \\
\hline AVHRR & MetOp-B & OSI SAF & L2P & $1 \mathrm{~km}$ & $6 \times 6$ & & $\begin{array}{l}\text { OSI } \\
\text { product OSI-204-b }\end{array}$ \\
\hline In situ & - & Various & - & - & None & & $\begin{array}{l}\text { Drifting/moored } \\
\text { buoys } \\
\text { in reference }\end{array}$ \\
\hline SEVIRI & MSG & OSI SAF & $\mathrm{L} 3 \mathrm{C}$ & $0.05^{\circ}$ & $6 \times 6$ & & $\begin{array}{l}\text { OSI } \\
\text { product OSI-206-a }\end{array}$ \\
\hline VIIRS & SNPP & NOAA OSPO & L3U & $0.02^{\circ}$ & $6 \times 6$ & [21] & Used in reference \\
\hline VIIRS & NOAA-20 & NOAA OSPO & L3U & $0.02^{\circ}$ & $6 \times 6$ & {$[21,22]$} & Used in reference \\
\hline SLSTR & Sentinel 3A & EUMETSAT & L2P & $1 \mathrm{~km}$ at nadir & $6 \times 6$ & & Dual view only \\
\hline SLSTR & Sentinel 3B & EUMETSAT & L2P & $1 \mathrm{~km}$ at nadir & $6 \times 6$ & & Dual view only \\
\hline
\end{tabular}

The in situ SST data used in OSTIA are those distributed in near real time through the WMO GTS and hence are from a mixture of sources including drifting and moored buoy platforms and ships. Near surface data from Argo profiles are not used as they are reserved for independent validation of the analyses. Satellite SST data from a variety of instruments are used. These are primarily infra-red (IR) sensors on polar orbiting satellites, which give accurate global SST data approximately two times per day but can suffer from data gaps where cloud occurs. Currently there are two exceptions to this in use in OSTIA: the Spinning Enhanced Visible Infra-Red Imager (SEVIRI) IR sensor on the Meteosat Second Generation (MSG) geostationary orbiting satellite, which provides more views per day of the Atlantic and western Indian Oceans than is possible from a polar orbiter, and the passive microwave instrument Advanced Microwave Scanning Radiometer 2 (AMSR2) on the polar orbiting GCOM-W (Global Change Observation Mission -Water) satellite, which has fewer data gaps than IR sensor data.

Sea ICs from the Ocean and Sea Ice Satellite Application Facility (OSI SAF; product OSI-401-b) based on Special Sensor Microwave Imager/Sounder (SSMI/S) data on DMSP-F18 are used, and lake ICs are taken from the National Center for Environmental Prediction (NCEP) dataset, which is based on multiple sensors. Since the daily input data files from these providers are normally spatially complete, there is no use of IC data from the days surrounding the analysis date.

\subsubsection{Satellite SST Data Processing}

The file format of the input satellite data follows the Group for High Resolution SST (GHRSST; www.ghrsst.org) data specification [18] and the data are hence supplied with auxiliary information that aids their use. The quality information provided with the data files is used in the OSTIA processing. Generally, data with the two highest quality levels (4 and 5) are used, but for Visible Infrared Imager Radiometer Suite (VIIRS) and SLSTR data only those data points with the highest quality level (5) are retained. Estimates of bias are also provided and are removed from the SSTs, and estimates of error standard deviation are saved for later use in the analysis.

As OSTIA attempts to estimate the foundation SST, it is undesirable to include data containing a significant diurnal signal. Satellite SSTs which may be affected by a diurnal signal are determined using wind information supplied with the data (if available) and are defined as daytime data with wind speed less than $6 \mathrm{~m} \mathrm{~s}^{-1}$. For all nighttime data, and daytime data where the wind speed is above this threshold, the SST below the surface is expected to approximate the skin SST, which is the temperature of the layer of the ocean that the IR sensors are sensitive to, except for a cool offset [23,24]. For IR sensor datasets where that offset is not already removed (currently only the Sea and Land Surface Temperature Radiometers (SLSTRs)), $0.17^{\circ} \mathrm{C}$ is added to the SSTs [1,24]. 
Satellite SST data tend to be oversampled compared to the grid used to produce OSTIA and the data assimilation scheme that is used to combine the data is not able to take into account any correlations in the errors in the input data. Therefore, the satellite SST data are thinned before ingestion into the OSTIA system (as shown in Figure 1, observation processing section). The amount of subsampling that is applied for each sensor is shown in Table 1. Typically one SST value in every six data points is retained in both spatial directions. However, this is reduced to one in every two points for the passive microwave AMSR2 instrument, which has coarser resolution than the IR sensors. In order to maximise the amount of data used in the analyses, the algorithm searches for a nearby valid SST to retain if the grid point that would have been kept does not contain a valid SST. A copy of the data is also made with a second thinning applied (Figure 1, bias estimation section). This retains the median SST where more than one value occurs within $13 \mathrm{~km}$ and $1 \mathrm{~h}$. These data with the second thinning applied are used for calculating satellite biases, which are estimated on a coarser grid than the SST analysis. The data without the second thinning are used for the SST analysis.

\subsubsection{Quality Control}

A quality control check of the data is carried out using a Bayesian scheme $[25,26]$ to evaluate the probability of a gross error in the data based on a comparison to the previous day's analysis field. Erroneous in situ data from instruments in ice covered regions can be missed by this test. Therefore, a check of the observation location against the previous day's IC field is done. If the IC is above $50 \%$, the observation is not used.

A reject list is also maintained and used to exclude in situ SST stations with persistent quality issues. The in situ SST stations that are on the reject list are updated monthly, based on observation minus OSTIA (o-O) statistics derived from the previous month's data. For stations that have reported more than 30 observations during the previous month, the mean, root mean square (RMS) and standard deviation o-O and the percentage of observations that failed quality control are compared to a number of thresholds to determine whether they should be added to, or removed from, the reject list (Figure 2).

The o-O threshold values depend on station type: for buoy SSTs the mean and standard deviation limits are $1.0 \mathrm{~K}$ and $1.5 \mathrm{~K}$ respectively and for ship SSTs thresholds of $1.5 \mathrm{~K}$ and $2.0 \mathrm{~K}$ apply. Stations whose o-O statistics are below both those thresholds and with quality control rejection rates less than $10 \%$ in the preceding month are marked as "good enough to remove" and will be removed from the reject list if already present on the list.

Next, each station's SST o-O statistics are checked against an alternative set of thresholds: $25 \%$ rejection rate and mean SST o-O of $1.5 \mathrm{~K}$ for buoys or $2.0 \mathrm{~K}$ for ships. Stations whose o-O statistics exceed either of those thresholds are marked as "bad enough to reject". Stations deemed "not good enough to remove" and "bad enough to reject" will be added to the reject list (or remain there if already present). Stations deemed "not good enough to remove" and "not bad enough to reject" are subject to a further sequence of checks on rejection rates and mean, standard deviation and RMS o-O to determine whether they should be accepted or rejected for the coming month.

If stations have reported 30 or fewer SST observations during the previous month, the procedure is instead applied to the previous two or three months of data if including these allows the number of observations criterion to be met. If not, stations remain on the reject list if they are already on it, otherwise they are accepted. 


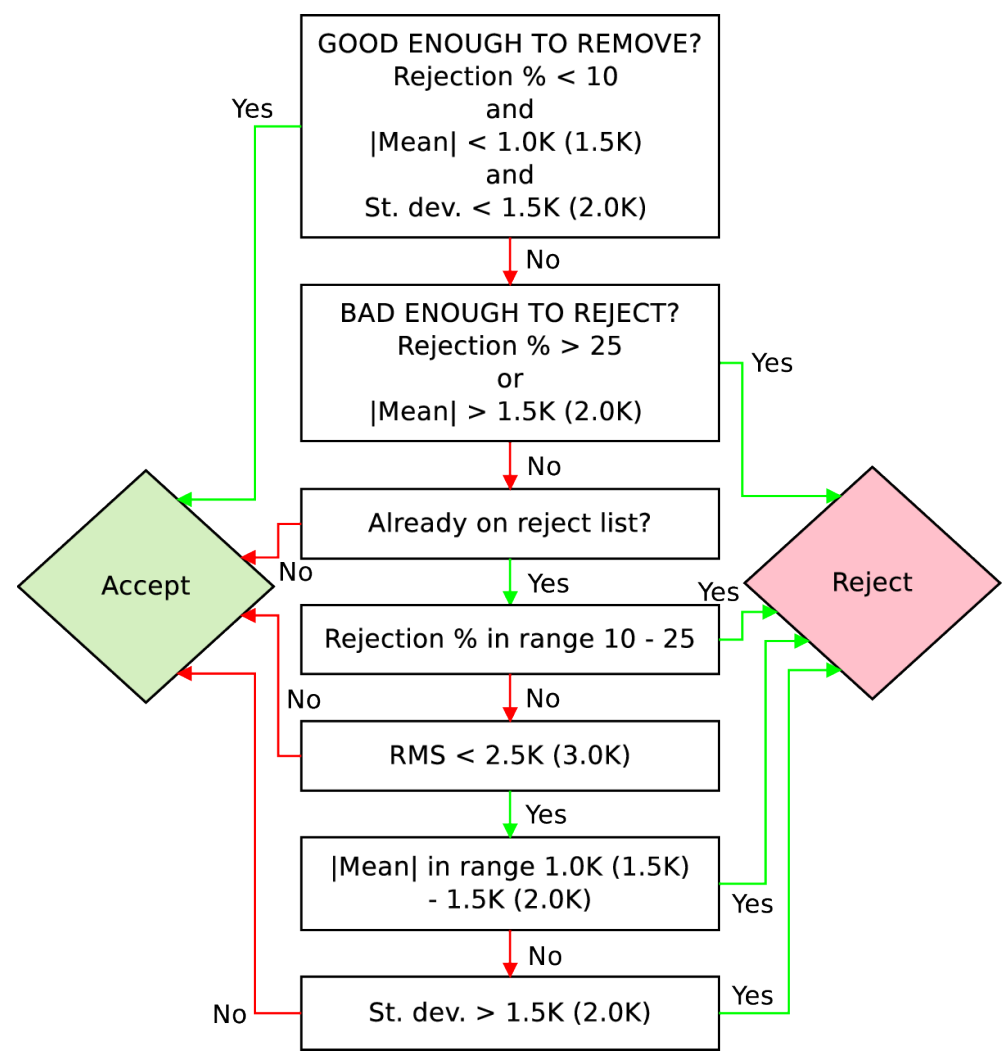

Figure 2. Decision process for determining if an in situ platform is added to or removed from a reject list. Decisions are based on the percentage of quality control rejections in the previous month and statistics of observation minus OSTIA differences. Buoy platforms and ships have different thresholds applied; the latter are given in parenthesis.

\subsection{Sea Ice Analysis}

Prior to February 2018, a simple regridding method had been used to process IC data. This reformatted the input data onto the final OSTIA output grid. However, this approach was vulnerable to missing data. Since February 2018 the NEMOVAR data assimilation analysis scheme is used in OSTIA to combine a background (first guess) IC field with daily satellite IC information. As described in $[14,17]$, this performs an iterative minimisation of the cost function given in Equation (1). In this, the cost $\mathrm{J}$ associated with a particular increment $\delta \mathbf{x}$ to the background (or first guess) field depends on the background error covariance matrix, $\mathbf{B}$, the difference between the observations and the background field, $\mathbf{d}$ and the observation error covariance matrix, $\mathbf{R}$. $\mathbf{H}$ is the observation operator, which interpolates the gridded data to the observation locations. Sixty iterations of the scheme are applied in order to ensure that it has converged to a solution.

$$
J(\delta \mathbf{x})=\frac{1}{2} \delta \mathbf{x}^{T} \mathbf{B}^{-1} \delta \mathbf{x}+\frac{1}{2}(\mathbf{d}-\mathbf{H} \delta \mathbf{x})^{T} \mathbf{R}^{-1}(\mathbf{d}-\mathbf{H} \delta \mathbf{x})
$$

The sea ice analysis is performed on the extended ORCA12 grid. The ORCA grids are tripolar, with each pole over land. In the ORCA12 case the grid has a nominal resolution of $\frac{1}{12}^{\circ}$ at the equator [27] and finer resolutions at increased latitudes [17,27]. The extended version of the grid is used as the standard version does not reach far enough south to include all the OSTIA ocean grid points. The background IC field is the previous day's analysis. The background error covariance matrix is not specified directly owing to its large size. Instead, the system is provided with estimates of the background error standard deviations and a lengthscale that describes the correlations in the background errors, which are modelled within the scheme using a diffusion operator that approximates a Gaussian function. The background error standard deviations are specified seasonally as shown in 
Figure $3 a, c, e, g$ and are interpolated in time to the date of each analysis. The estimates of background error standard deviation are largest near the boundaries between open water and ice and are lower away from the expected position of the ice edge. The lengthscale that specifies the correlations in the background errors is set to $0.4^{\circ}$.

As stated previously, OSI SAF and NCEP data are used for sea and lake IC respectively. To filter out spurious low concentration ice in the OSI SAF data, concentrations below $10 \%$ are set to zero. At present, uncertainty information provided with the data is not used. Instead, the fields shown in Figure $3 \mathrm{~b}, \mathrm{~d}, \mathrm{f}, \mathrm{h}$ are interpolated to the data locations and used as the estimates of error standard deviations. These fields have similar spatial patterns to the background error standard deviation fields but are smaller in magnitude. Errors in the input data are assumed uncorrelated by the data assimilation scheme.

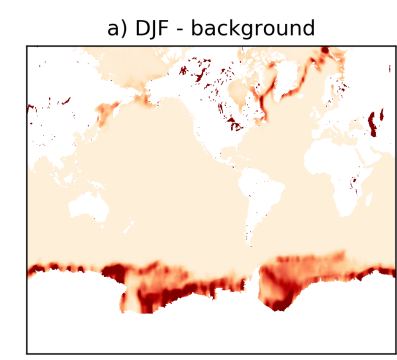

c) MAM - background

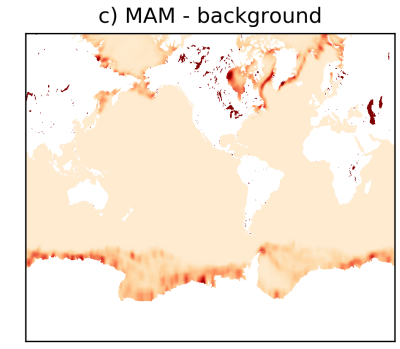

e) JJA - background

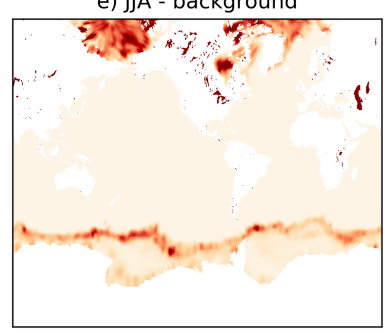

g) SON - background

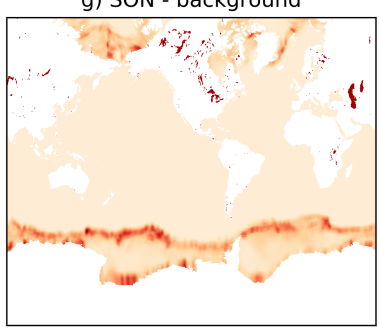

b) DJF - observations

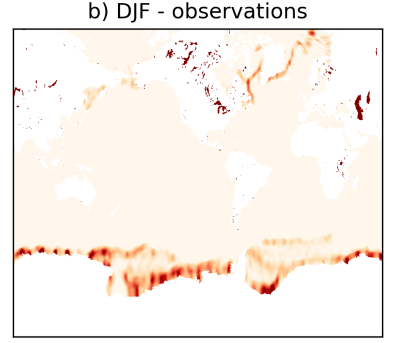

d) MAM - observations

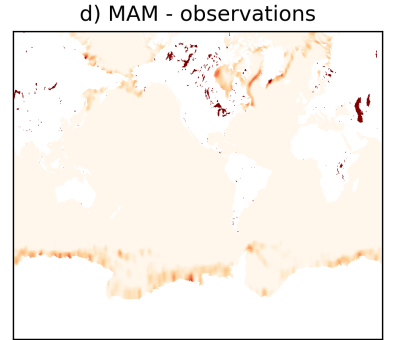

f) JJA - observations

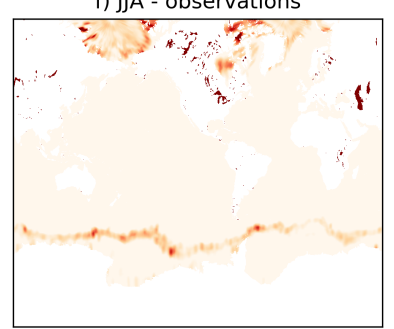

h) SON - observations

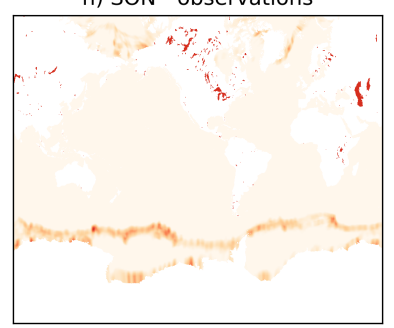

$\begin{array}{llllll}0.05 & 0.06 & 0.07 & 0.08 & 0.09 & 0.10\end{array}$

Figure 3. Error standard deviations used for the IC analysis for (a) the background in the December-January-February season and (b) the observations during the same season. $(\mathbf{c}, \mathbf{d})$ : as $(\mathbf{a}, \mathbf{b})$ expect for March-April-May; (e,f): June-July-August; and (g,h): September-October-November. 
The OSI SAF input data employs a more conservative land-sea mask than OSTIA. This causes an issue in the OSTIA analyses as near-coastal grid points do not get directly influenced by the input data causing spuriously low ICs. This is remedied by modifying the NEMOVAR outputs. In most regions, this is done by infilling the affected grid points from those that are within the realm of the OSI SAF ice data. Figure 4 shows the affected points in the North Sea. The green grid points are infilled from the values in the dark blue grid points. However, in the Baltic Sea the area covered by the input data is too small to do this (grey grid points in Figure 4). Instead the SST analysis is used in combination with a monthly freezing temperature climatology to determine if ice is likely to be present. The ocean freezing temperature climatology was derived from a monthly global 1 degree salinity climatology (Polar science center Hydrographic Climatology (PHC) 3.0, updated from [28]) and Equation (2) (from [29]) as follows:

$$
T_{f}=a_{0} S+a_{1} S^{\frac{3}{2}}+a_{2} S^{2}+b p
$$

In this equation the freezing temperature $T_{f}$ is dependent on salinity, $S$, coefficients $a_{0}=-0.0575$, $a_{1}=0.001710523 \mathrm{e}-3, a_{2}=-0.0002154996$ and $\mathrm{b}=-0.000753$, and pressure, $p$, which was set to $10.0 \mathrm{dbar}$. Freezing temperature for lakes was set to $0{ }^{\circ} \mathrm{C}$. The result is shown in Figure 5. A small tolerance is added to these freezing temperatures to accommodate errors in the temperature analyses. The tolerance is 0.01 and $0.1{ }^{\circ} \mathrm{C}$ for ocean and lakes respectively. If the temperature is below the calculated freezing point, IC is set to be $100 \%$. It is removed at a rate of $20 \%$ per day once SST rises above freezing. The procedure to add ice if temperature is below freezing is also applied to all lakes (e.g., brown points in Figure 4).

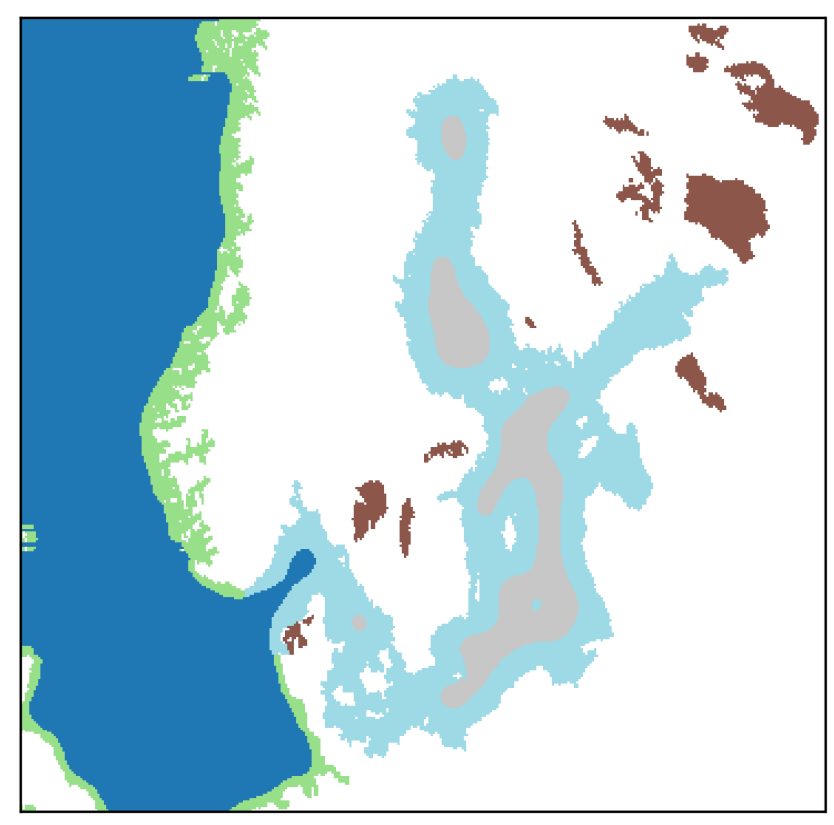

Figure 4. Baltic and North Sea region of the mask used to determine which sea ice analysis grid points require additional processing. Green points are coastal and are not sufficiently covered by the input data. These are infilled from the dark blue regions. In the Baltic Sea, only the grey region is covered by the input data. This and the light blue region are augmented by using the SST to determine if ice is present. This method to infer ice from the temperature is also applied to lakes (brown regions). 


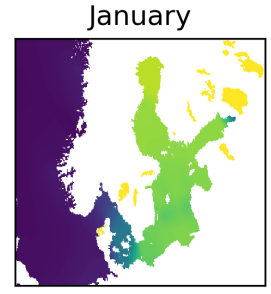

April

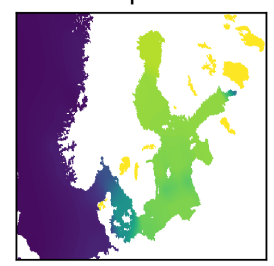

July

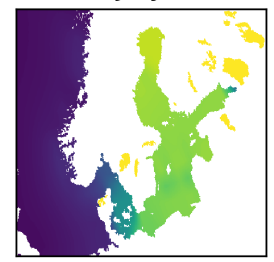

October

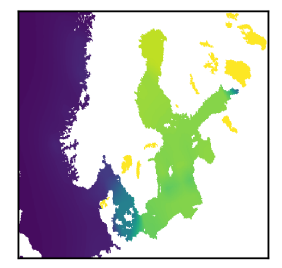

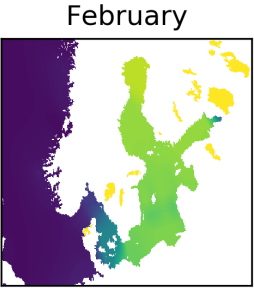

May

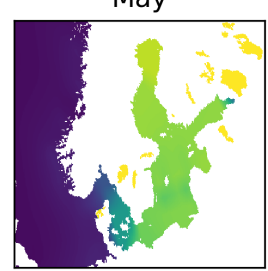

August

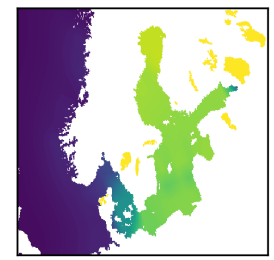

November

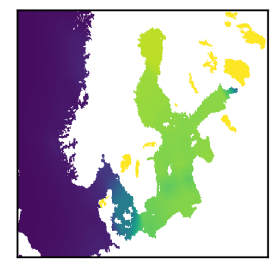

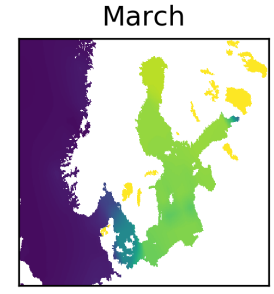

June

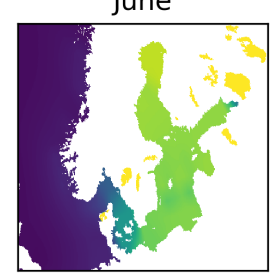

September

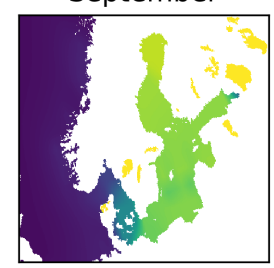

December

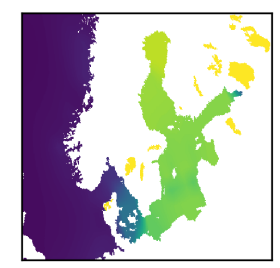

$-2.00-1.75-1.50-1.25-1.00-0.75-0.50-0.250 .00$

Freezing temperature $\left({ }^{\circ} \mathrm{C}\right)$

Figure 5. Monthly freezing temperature climatology for the Baltic Sea and part of the North Sea. Variations between months are small with the largest changes occurring in the Kattegat and surrounding area.

\subsection{Satellite SST Bias Estimation}

In this processing step, drifting and moored buoy in situ data and nighttime data from the VIIRS sensor are used together as a reference dataset. Matchups are then found between the reference dataset and each of the other satellite SST data types, including the remainder of the VIIRS dataset. The limits for a matchup to occur are $25 \mathrm{~km}$ and 1 day. The two VIIRS sensors currently have a single bias field associated with them, and the same is done for the two SLSTR sensors, since testing indicated that there was no advantage to generating separate bias fields for each. However, this may be reviewed in the future.

For each sensor a spatial analysis of the matchups is performed. This is done using NEMOVAR, as described in Section 2.2 but no land mask is used and it is performed on the extended ORCA025 grid. This grid is a coarser (nominal resolution $\frac{1}{4}^{\circ}$ ) version of the grid used for the sea ice and SST analyses. The background to each bias analysis is the previous day's bias field for that sensor but with the magnitudes of the biases reduced by $10 \%$. This reduction means that in the absence of matchups the bias fields will eventually relax to zero.

The background error standard deviations used in the bias analyses are set to $0.1^{\circ} \mathrm{C}$ globally and the length scale that defines the correlations in the background errors is defined as $7^{\circ}$. The matchup error standard deviations are defined as shown in Figure 6 and vary spatially with higher values in 
more variable regions. These error variances were tuned to ensure that the results approximate the bias fields generated under the previous version of the system, prior to the use of NEMOVAR, described in [1]. An example of a bias field is shown in Figure 7. This shows the estimate of the bias in SLSTR data for 1 October 2019 (biases were estimated from Sentinel 3A data only since Sentinel 3B SLSTR data were not used operationally at the time).
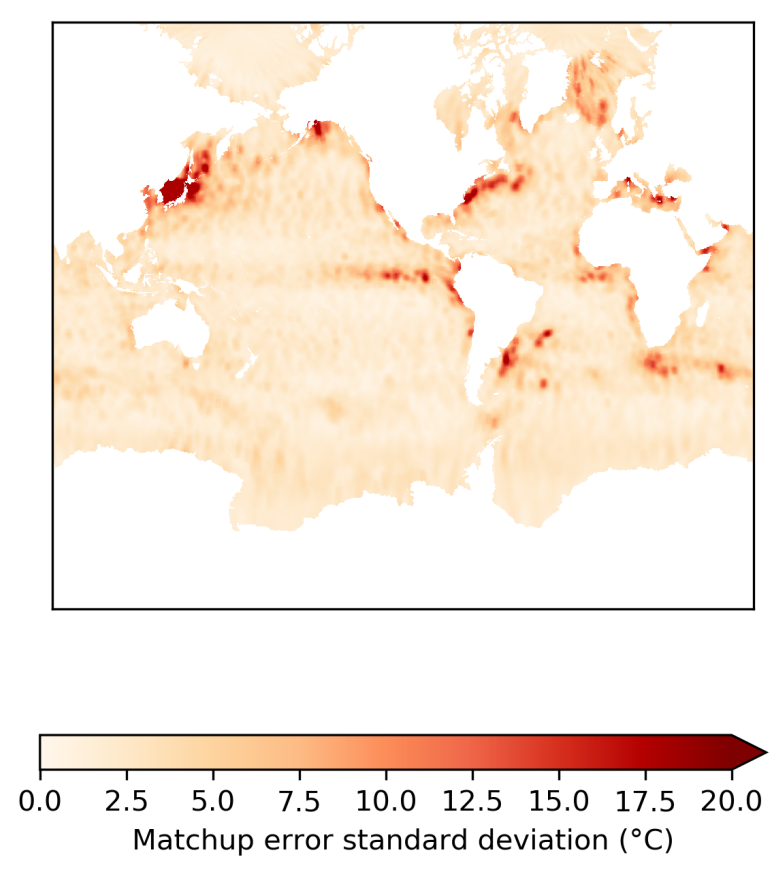

Figure 6. Error standard deviations specified for the matchups between the reference dataset and the sensors to be bias corrected.

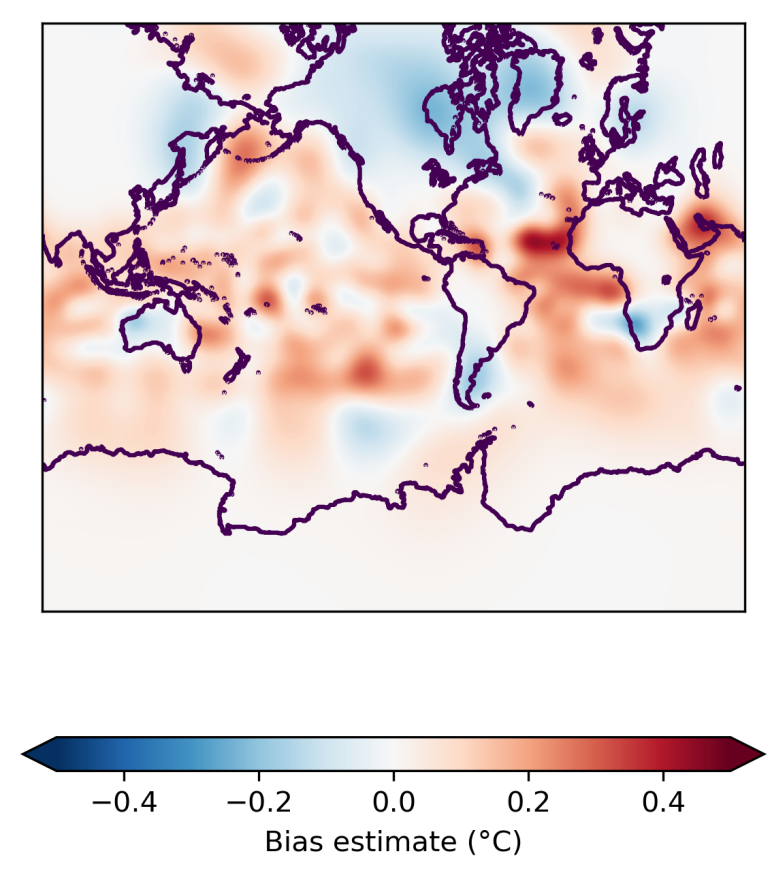

Figure 7. Bias field for the Sentinel 3A SLSTR data for 1 October 2019. Land boundaries are shown, but the analysis is generated without a land-sea mask and so the bias estimates extend over the land. 


\subsection{Analyses of SST Data}

\subsubsection{Temperature Analysis}

As with the IC analysis, the SST analysis is generated using NEMOVAR on the extended ORCA12 grid. It uses as input the satellite data after removal of the biases calculated in Section 2.3 and the in situ SSTs. The uncertainty information provided with satellite SSTs is used to define the diagonal elements of $\mathbf{R}$ from Equation (1). For in situ SSTs, spatially varying error standard deviations are prescribed (Figure 8a) and an additional platform-dependent uncertainty is combined with this in quadrature as defined in [16]. In that study, the additional platform-dependent error variance in moored buoys and ships compared to drifters is found to be 0.12 and $0.19{ }^{\circ} \mathrm{C}^{2}$ respectively. The same platform-dependent uncertainty used for moored buoys is now also added for drifting buoy data owing to concerns over over-fitting to these data in the NEMOVAR implementation.
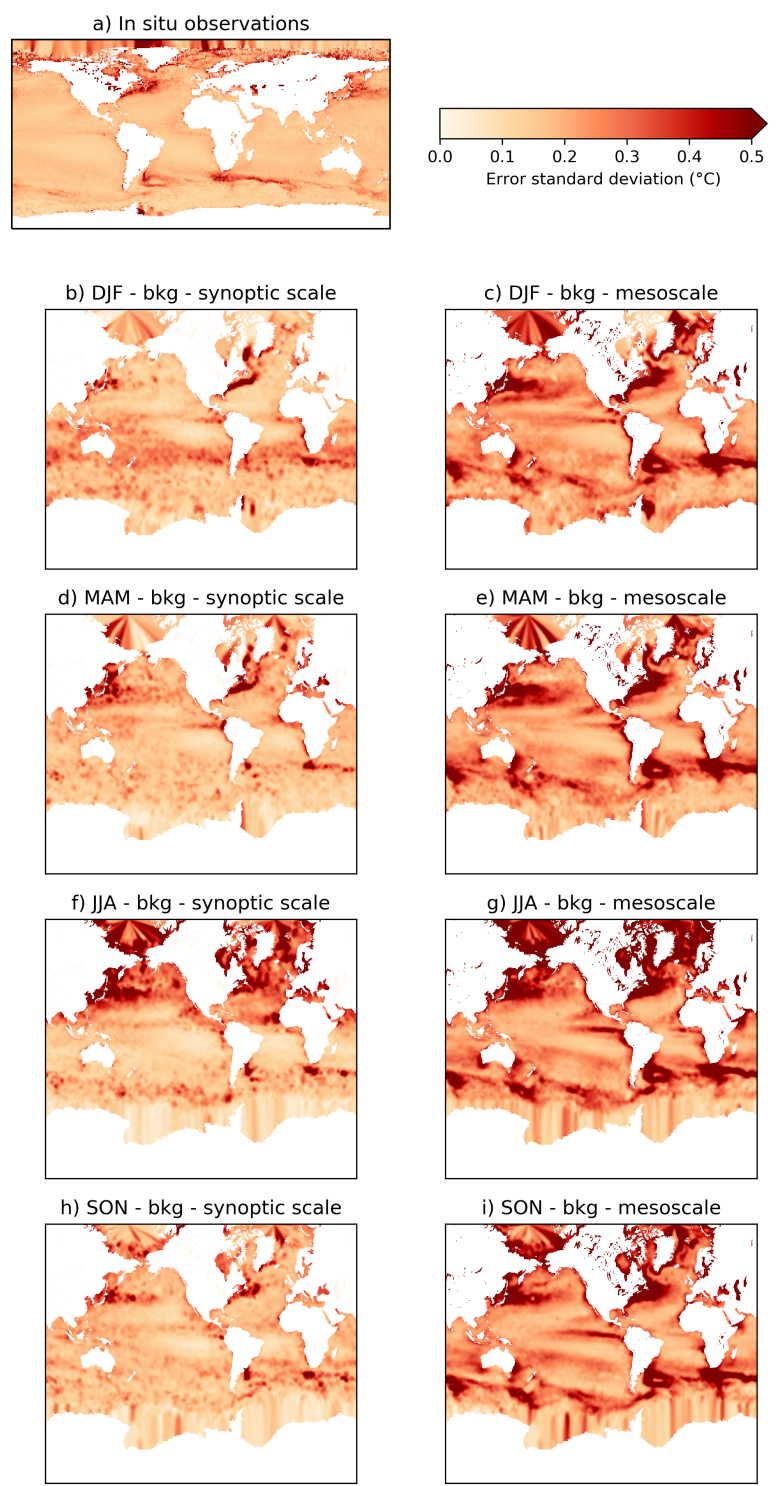

Figure 8. Error standard deviations used for the SST and observation influence analyses: (a) observation error standard deviation used for in situ observations; (b) the component of the background (bkg) errors that is correlated on synoptic scales in the December-January-February season and (c) the component that is correlated at mesoscales. (d,e) as $(\mathbf{b}, \mathbf{c})$ except for March-April-May; $(\mathbf{f}, \mathbf{g})$ as $(\mathbf{b}, \mathbf{c})$ except for June-July-August; and $(\mathbf{h}, \mathbf{i})$ as $(\mathbf{b}, \mathbf{c})$ except for September-October-November. 
The background for the analysis on day $i, \mathbf{x}_{i}^{b}$, is generated by a damped persistence of anomalies from the SST analysis from the previous day, $\mathbf{x}_{i-1}^{a}$, as described in Equation (3). The anomalies are the difference between the analysis and a climatological field for that day $\mathbf{x}_{i-1}^{c}$, which are reduced by a factor $0.1^{\frac{1}{t}}$, where $t$ is a timescale. The climatological field for the analysis day, $\mathbf{x}_{i}^{c}$, is then added to give the background field.

$$
\mathbf{x}_{i}^{b}=0.1^{\frac{1}{t}}\left(\mathbf{x}_{i-1}^{a}-\mathbf{x}_{i-1}^{c}\right)+\mathbf{x}_{i}^{c}
$$

The daily climatology is derived from a reprocessed version of OSTIA [6] and is averaged over the period 1985 to 2007. The timescale, $t$, for regions that have $50 \%$ IC or less (according to the ice analysis) is set to 30 days, which means that the anomalies will decay to $92.6 \%$ of their original size after a day and to $10 \%$ after 30 days. For regions with greater than $50 \%$ concentration the background is relaxed towards $-1.8{ }^{\circ} \mathrm{C}$ in the ocean and $0.1^{\circ} \mathrm{C}$ in lakes with a timescale that depends on the IC. If the IC is $50 \%$ the timescale is 17.5 days and if the IC is $100 \%$ it is 5 days, with a linear change between these values. The resulting background field is checked for extreme SST values. Any values less than $-2{ }^{\circ} \mathrm{C}$ or greater than $40{ }^{\circ} \mathrm{C}$ are reset to those values. Finally, a weak smoothing is applied to the field using a Gaussian filter with lengthscale $4.7 \mathrm{~km}$.

The background error covariances are specified using a dual-component formulation developed for NEMOVAR by [30] and the OSTIA implementation is described in detail in [17]. As with the single-component configurations described in Sections 2.2 and 2.3, the inputs to NEMOVAR are spatially varying background error standard deviations and a lengthscale, but in this case two are provided instead of one. The background error standard deviations are from [16] and vary seasonally. The error variances have been smoothed to reduce noise while retaining structure using an inverse distance weighting filter (with weights defined as $\frac{1}{d+1}$, where $\mathrm{d}$ is the distance from the central point in units of number of grid cells) and a $61 \times 61$ kernel. These background error standard deviations are shown in Figure $8 \mathrm{~b}-\mathrm{i}$. The two uncertainty components for each season are designed to approximately represent errors that correlate on atmospheric synoptic scales and ocean mesoscales or shorter. Their associated lengthscales are currently $2.7^{\circ}$ and $0.135^{\circ}$ respectively (the latter was set to $0.36^{\circ}$ in the initial implementation of the NEMOVAR version of OSTIA but was reduced following the work of [17] to improve the representation of features in the OSTIA analyses). The background error standard deviations control the relative weights of the two components and therefore the effective correlation lengthscale of the background errors varies spatially.

The OSTIA system takes advantage of the dual-component setup to reduce the effective background error correlation lengthscale in certain situations by increasing the relative weight given to the shorter lengthscale uncertainty component. The first of these ramps up the relative weight given to the shorter lengthscale for temperatures between $3{ }^{\circ} \mathrm{C}$ and $1{ }^{\circ} \mathrm{C}$ to prevent the spreading of warm SST observation information under ice. The second modification ramps down the weighting of the longer lengthscale uncertainty component for distances less than $400 \mathrm{~km}$ from the coast. The final modification is a flow-dependent adjustment developed by [17]. This ramps up the relative weighting given to the shorter lengthscale uncertainty component where the SST gradients in the background field are between 20 and $50 \mathrm{mK} \mathrm{km}{ }^{-1}$. This allows the background error correlations to adapt daily to the changing SST conditions, rather than them changing only on a seasonal timescale, and improves the representation of features in the SST analyses.

Finally, the resulting SST analysis is checked for unrealistic low temperature, defined as those less than $-2{ }^{\circ} \mathrm{C}$, and these are reset to that limit if they occur.

\subsubsection{Observation Influence Analysis}

A second analysis is performed using the same inputs as the original SST analysis but with all background values set to zero and all observation values set to one. This "observation influence" analysis has values close to one where the input data strongly influenced the SST analysis and zero in the absence of observations (which means that the analysis would be the background value in 
that location). Intermediate values imply that the analysis was a balance between the input data and the background. The observation influence analysis values are reset to 0 or 1 if values less than or greater than these occur. As the background to the analysis does not contain the SST values in this case, the observation influence analysis does not include the ramping applied to the background uncertainty components where the SST gradients are high or the ice edge is near but is otherwise equivalent to the SST analysis. This is used to generate an analysis uncertainty estimate as described in Section 2.5. An example of an observation influence analysis is shown in Figure 9.

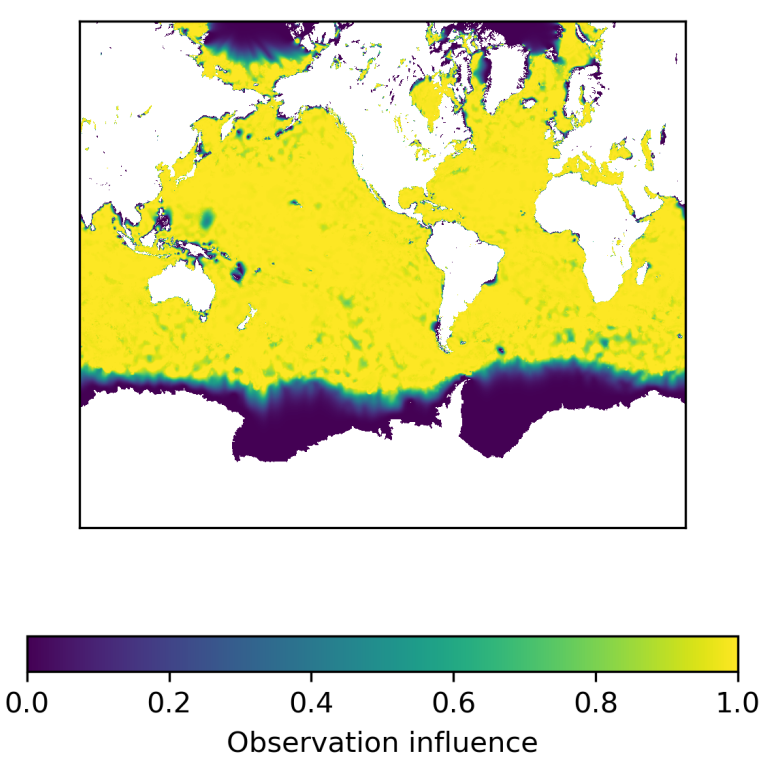

Figure 9. Example of an observation influence analysis.

\subsection{Postprocessing}

The final step in the OSTIA processing chain is to postprocess all the outputs before dissemination to users. All the previous steps produce data on the extended ORCA025 and ORCA12 grids and these are bilinearly interpolated to a regular grid using weights generated by the SCRIP package (https://github.com/SCRIP-Project/SCRIP).

An SST uncertainty estimate is derived from the observation influence analysis described in Section 2.4 using Equation (4) (reproduced from [1]).

$$
\epsilon_{i}^{a}=\sqrt{B_{i}\left[\alpha+\beta\left(1-\epsilon_{i}^{o}\right)\right]}
$$

The analysis uncertainty $\epsilon_{i}^{a}$ at each grid point $i$ depends on the total background error variance (the combination of the mesoscale and synoptic scales), $B_{i}$, and the observation influence analysis, $\epsilon_{i}^{o}$, at that grid point and two tuning parameters $\alpha$ and $\beta$, which are set to 0.5 and 4 respectively.

The various outputs to the system are combined in a netCDF file that follows the GHRSST data specification version 2 (GDS2) [18] before disseminating the data to users. These files are described in Section 3 below.

\section{Results}

The OSTIA system is run daily at 05:50 UTC to create SST and IC analyses for the previous day. Inputs and outputs from the system are monitored routinely to ensure that data are produced on time and with consistent quality. An automated system triggers an alert if there is a lack of data from a sensor for a significant amount of time and, if appropriate, operators contact data providers to ask them to investigate the issue. Monitoring of outputs typically consists of examining plots of 
observation-minus-background differences, as well as time series of globally and regionally aggregated statistics of these. Plots of the output fields are also available to view by the monitoring operative. Issues are dealt with as appropriate, for example by contacting data providers or by adding an in situ platform to a reject list.

The primary OSTIA output is a GDS2 netCDF file. The variables within the data file are summarised in Table 2. Data are provided on a $\frac{1}{20}^{\circ}$ regular grid and there is one daily analysis per file, which means that the dimensions are 1 in time, 3600 in latitude and 7200 in longitude. An example of each of the data fields is shown in Figure 10.

Table 2. Variables contained in the main OSTIA output files. Some of the variables are stored as packed data, which means that they have to be multiplied by their scale_factor attribute and the add_offset attribute added in order to obtain the actual numbers.

\begin{tabular}{lll}
\hline Variable Name & Dimensions & Notes \\
\hline time & 1 & Nominal time that the SST analysis represents \\
lat & 3600 & Central latitudes of the grid points \\
lon & 7200 & Central longitudes of the grid points \\
analysed_sst & $1 \times 3600 \times 7200$ & The SST analysis (packed data) \\
analysis_error & $1 \times 3600 \times 7200$ & The uncertainty in the SST analysis (packed data) \\
sea_ice_fraction & $1 \times 3600 \times 7200$ & The IC analysis (packed data) \\
mask & $1 \times 3600 \times 7200$ & Water / land / lake / ice mask \\
\hline
\end{tabular}

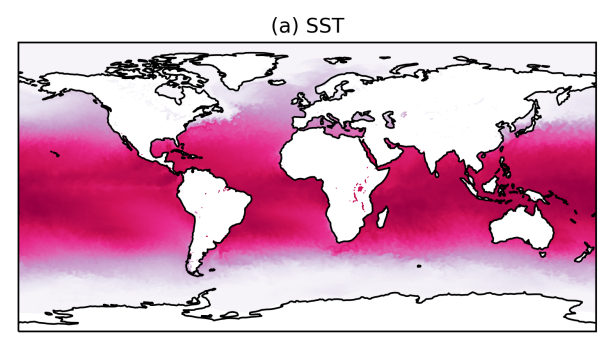

(b) SST uncertainty
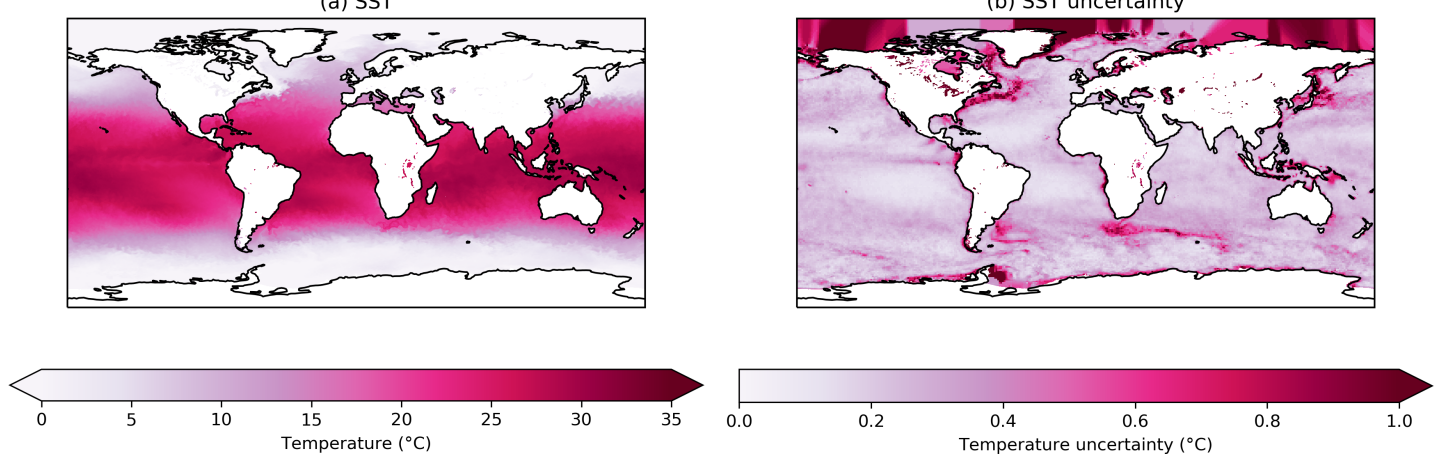

(c) Ice concentration
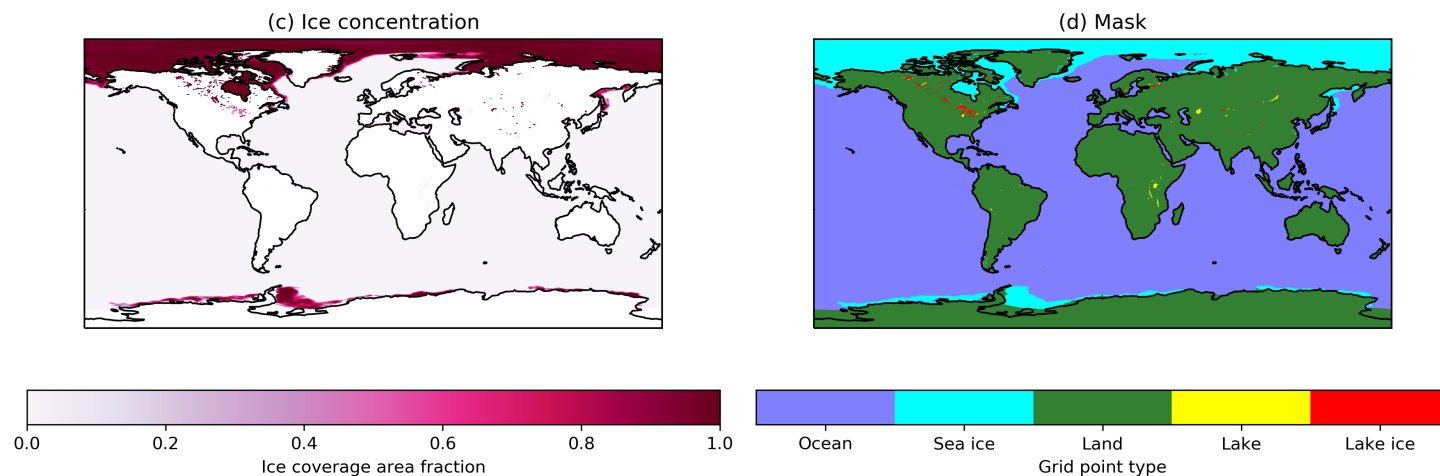

Figure 10. Example outputs from the OSTIA system for 1 February 2019.

The regridded versions of the SSTs, SST uncertainties and ICs are packed into a lower precision data type to reduce file size. To obtain the actual SSTs and IC, the data in the file have to be multiplied by their scale_factor attribute and the add_offset attribute then added. This is done automatically by some netCDF data readers. 
The mask variable provides the user with information on which grid points are ocean (mask value 1) or not (mask value 2). Information on lakes and ice is also encoded in the variable by adding 4 to the mask values of lake grid points and 8 to the mask values in icy areas (defined as ICs greater than zero).

In addition to the output described above, products are generated on a $\frac{1}{4}^{\circ}$ regular grid in a similar netCDF format: monthly and seasonal averages; the satellite bias estimates and an anomaly file containing differences between the analyses and a climatology of AVHRR Pathfinder data [31]. These and the primary output files are all available from the Copernicus Marine Environment Monitoring Service (CMEMS, marine.copernicus.eu).

\section{Discussion}

The OSTIA system has changed in a number of ways since it was described by [1]. The impact of these developments is illustrated in Figure 11. This shows global and regional monthly standard deviations of matchups between the OSTIA analyses and Argo data [32] in the range 3-5 $\mathrm{m}$ from the EN4 dataset [33]. Near surface Argo observations have been shown to be representative of foundation SST [34] and, as stated previously, Argo data are not used to generate the analyses, allowing their use as an independent reference for validation. The latest version of OSTIA performs well compared to the older versions of the system and also in comparison to other SST analyses (e.g., see the NOAA SST quality monitor (SQUAM); https:/ /www.star.nesdis.noaa.gov/sod/sst/squam/analysis/14 [35,36]). Some of the most significant events in the evolution of OSTIA are shown in Figure 11 by vertical lines. The changes in the statistics associated with each OSTIA change gives insight into the relative importance of each update.

The importance of the bias corrections applied to the satellite SST data can be seen by the change in statistics as the satellite reference sensor changes. In early 2012 the Advanced Along-Track Scanning Radiometer (AATSR) data stream was lost. This was in use as the reference sensor, leading to the switch to using MetOp-A AVHRR data instead. The Argo statistics noticeably worsened after this in some regions (for example, the South Atlantic), although the effect is less clear globally and in the North Atlantic there is an indication of improvement in the statistics. In September 2016, the reference sensor changed again to VIIRS. This corresponds to an improvement in the Argo statistics globally and in most regions.

Between the two changes to the reference sensor, in January 2013, the background error covariances were updated and the number of assimilation scheme iterations were increased as described by [16], who found that these changes yielded improved Argo validation statistics. While there is some indication of this improvement in Figure 11 (e.g., in the Southern Ocean), it is not clear owing to the short amount of time between changes.

The data assimilation scheme was changed to NEMOVAR in February 2018 and updates were made to improve the SST feature resolution in March 2019. The recent changes have both corresponded to improvements in the Argo statistics in some regions, demonstrating the positive impact they have had. The latest system also represents sharper SST features than previous versions [17].

The improved performance of the current OSTIA system is therefore attributable to a number of factors. The switch to using VIIRS as the reference sensor, the update of the assimilation scheme to NEMOVAR and the change to the feature resolution all regionally resulted in noticeable improvements in the Argo statistics. However, globally, the reference sensor change had the most impact. The OSTIA system is expected to continue to improve in the future with current efforts focused on improving the reference dataset further by using SLSTR SSTs. 


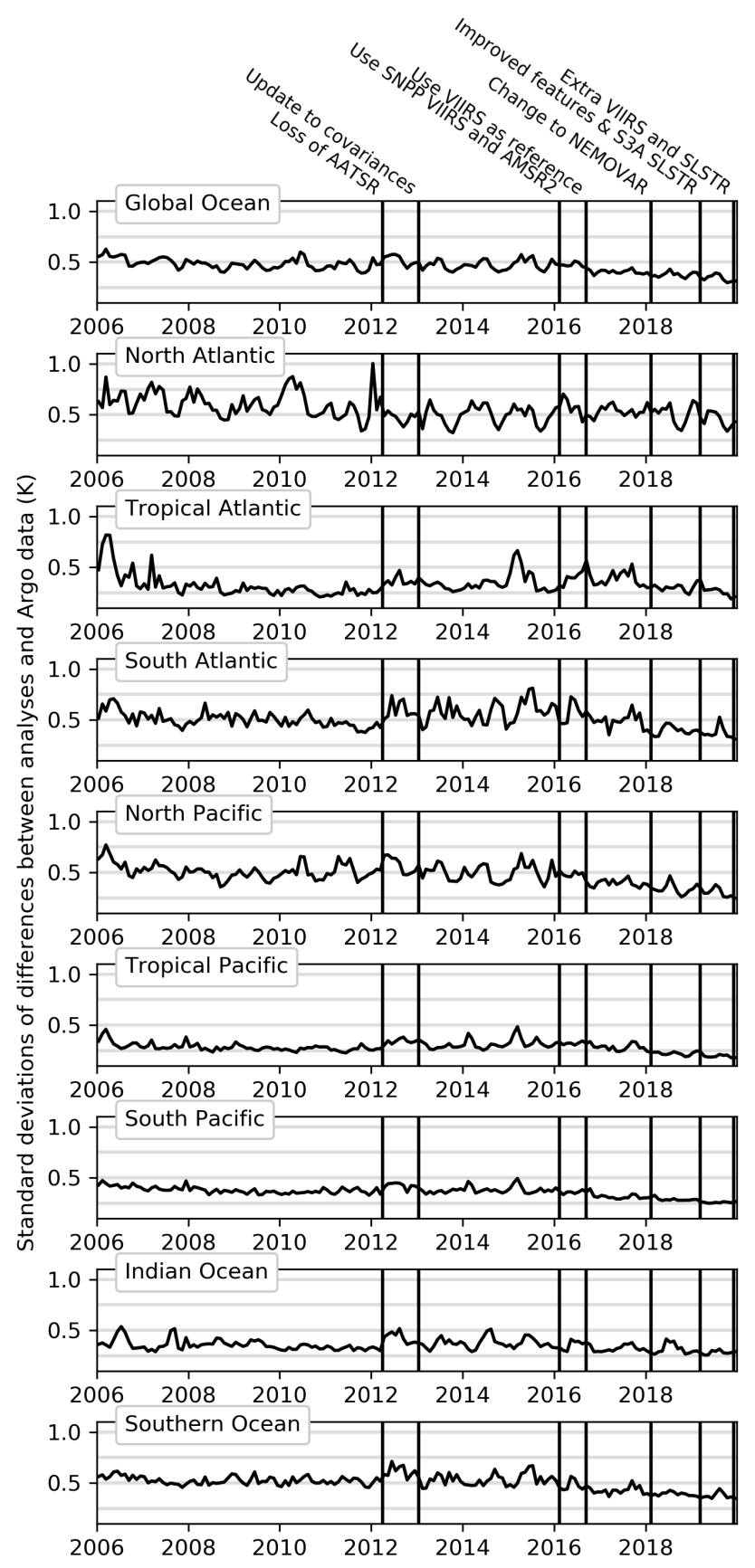

Figure 11. Monthly standard deviations of differences between near-surface Argo data and OSTIA foundation SST analyses for different regions. Some of the most notable changes to the OSTIA system are marked by vertical lines. Grey horizontal lines are drawn to aid comparison of the performance of OSTIA at different times.

\section{Conclusions}

The OSTIA system produces foundation SST and IC information in near real time for use in applications such as NWP. It is continuously developed and updated, both in terms of the input data it uses and the methods used to generate the products and has changed considerably since [1] originally described it. This technical note has explained the current configuration of the system. 
In summary, the system now uses the NEMOVAR data assimilation scheme to generate model-free analyses of foundation SST and IC. The input data to each analysis are a forecast of the SST or IC based on the previous day's analysis, satellite data and (in the case of SST) in situ data. The satellite SST data are bias corrected using a combination of in situ data and VIIRS nighttime satellite data. Background error covariances are prescribed seasonally and, for SST, updated daily using information from the background field. Uncertainty estimates that are provided with the satellite SST data are used, but uncertainties are prescribed for IC and in situ SST data. An SST analysis uncertainty estimate is produced using a special "observation influence" analysis, which reveals where observations have affected the analysis on each day.

Finally, while this technical note has focused on the near real time OSTIA system that describes the foundation SST, users may wish to be aware that in near real time an hourly diurnal skin SST analysis is also generated [9] and an ensemble of the global SST analyses produced around the world is created to support intercomparison activities [37]. The system is also used to create historical datasets of foundation SST (the dataset resulting from an old version of the OSTIA system is described in [6]) and as part of ESA's Climate Change Initiative to generate fields that represent the daily average SST at $20 \mathrm{~cm}$ depth $[7,8]$.

Data are disseminated to users by the Copernicus Marine Environment Monitoring Service (CMEMS; marine.copernicus.eu) under the Copernicus Marine Service Licence (http://marine. copernicus.eu/services-portfolio/service-commitments-and-licence/). The OSTIA foundation SST data are also available from the Physical Oceanography Distributed Active Archive Center (PO.DAAC; dataset link: https:/ / doi.org/10.5067/GHOST-4FK02).

Author Contributions: Methodology, S.G., E.F., C.M., M.M., A.M., J.R.-J., J.W. (Jennifer Waters); software, S.G., E.F., C.M., A.M., J.R.-J., T.S., J.W. (James While); validation, S.G., E.F., C.M. R.R., J.R.-J., T.S., M.W.; writing-original draft preparation, S.G., A.M.; writing-review and editing, S.G., E.F., M.M. All authors have read and agreed to the published version of the manuscript.

Funding: This work was funded by the UK's Public Weather Service and supported by grants under the Copernicus Marine Environment Monitoring Service (OSI-TAC; 78-CMEMS-TAC-SST) and through the European Space Agency Sea Surface Temperature Climate Change Initiative (4000101570/10/I?AM; 4000109848/13/I-NB).

Acknowledgments: Thank you to Jemma Davie for reviewing the description of the reject list procedure to ensure that it accurately reflects the "Monitoring and Updating Station Lists" (MUSLi) system and its documentation. We also thank the four reviewers for their useful comments, which improved the manuscript. AMSR data are produced by Remote Sensing Systems and were sponsored by the NASA AMSR-E Science Team and the NASA Earth Science MEaSUREs Program. Data are available at www.remss.com. OSI-204-b and OSI-206-a SST data and OSI-401-b sea IC data are products of the EUMETSAT Ocean and Sea Ice Satellite Application Facility (OSI SAF, www.osi-saf.org) and are copyright EUMETSAT. AVHRR Pathfinder data were provided by GHRSST and the US National Oceanographic Data Center - this project was supported in part by a grant from the NOAA Climate Data Record (CDR) Program for satellites. We thank the providers of in situ data who make their data available in near real time through the WMO GTS system. The Argo data used in this publication were collected and made freely available by the International Argo Program and the national programs that contribute to it. (http:/ / www.argo.ucsd.edu, http:/ / argo.jcommops.org). The Argo Program is part of the Global Ocean Observing System.

Conflicts of Interest: The authors declare no conflict of interest. The funders had input into decisions on updates to the OSTIA system but no influence on the writing of this manuscript, or in the decision to publish these results. 


\section{Abbreviations}

The following abbreviations are used in this manuscript:

$\begin{array}{ll}\text { AMSR } & \text { Advanced Microwave Scanning Radiometer } \\ \text { AVHRR } & \text { Advanced Very High Resolution Radiometer } \\ \text { CDR } & \text { Climate Data Record } \\ \text { DMSP } & \text { Defense Meteorological Satellite Program } \\ \text { EUMETSAT } & \text { European Organisation for the Exploitation of Meteorological Satellites } \\ \text { GCOM-W } & \text { Global Change Observation Mission - Water } \\ \text { GHRSST } & \text { Group for High Resolution SST } \\ \text { L2P } & \text { Level 2 Preprocessed } \\ \text { L3U } & \text { Level 3 Uncollated } \\ \text { L3C } & \text { Level 3 Collated } \\ \text { MetOp-B } & \text { Meteorological operational satellite B } \\ \text { MSG } & \text { Meteosat Second Generation } \\ \text { NAVO } & \text { Naval Oceanographic Office } \\ \text { NCEP } & \text { National Centers for Environmental Prediction } \\ \text { NOAA } & \text { National Oceanographic and Atmospheric Administration } \\ \text { OSI SAF } & \text { Ocean and Sea Ice Satellite Application Facility } \\ \text { OSPO } & \text { Office of Satellite and Product Operations } \\ \text { REMSS } & \text { Remote Sensing Systems } \\ \text { SEVIRI } & \text { Spinning Enhanced Visible Infra-Red Imager } \\ \text { SLSTR } & \text { Sea and Land Surface Temperature Radiometer } \\ \text { SNPP } & \text { Suomi National Polar-orbiting Partnership } \\ \text { SSMI/S } & \text { Special Sensor Microwave Imager / Sounder } \\ \text { SST } & \text { Sea Surface Temperature } \\ \text { WMO } & \text { World Meteorological Organisation } \\ \text { VIIRS } & \text { Visible/Infrared Imager Radiometer Suite } \\ & \end{array}$

\section{References}

1. Donlon, C.J.; Martin, M.; Stark, J.; Roberts-Jones, J.; Fiedler, E.; Wimmer, W. The Operational Sea Surface Temperature and Sea Ice Analysis (OSTIA) system. Remote Sens. Environ. 2012, 116, 140-158. [CrossRef]

2. Balmaseda, M.A.; Mogensen, K.; Weaver, A.T. Evaluation of the ECMWF ocean reanalysis system ORAS4. Q. J. R. Meteorol. Soc. 2013, 139, 1132-1161. [CrossRef]

3. Dee, D.P.; Uppala, S.M.; Simmons, A.J.; Berrisford, P.; Poli, P.; Kobayashi, S.; Andrae, U.; Balmaseda, M.A.; Balsamo, G.; Bauer, P.; et al. The ERA-Interim reanalysis: Configuration and performance of the data assimilation system. Q. J. R. Meteorol. Soc. 2011, 137, 553-597. [CrossRef]

4. Petch, J.C.; Short, C.J.; Best, M.J.; McCarthy, M.; Lewis, H.W.; Vosper, S.B.; Weeks, M. Sensitivity of the 2018 UK summer heatwave to local sea temperatures and soil moisture. Atmos. Sci. Lett. 2020, e948. [CrossRef]

5. Schneemann, J.; Rott, A.; Dörenkämper, M.; Steinfeld, G.; Kühn, M. Cluster wakes impact on a far-distant offshore wind farm's power. Wind Energy Sci. 2020, 5, 29-49. [CrossRef]

6. Roberts-Jones, J.; Fiedler, E.K.; Martin, M.J. Daily, Global, High-Resolution SST and Sea Ice Reanalysis for 1985-2007 Using the OSTIA System. J. Clim. 2012, 25, 6215-6232. [CrossRef]

7. Merchant, C.J.; Embury, O.; Roberts-Jones, J.; Fiedler, E.; Bulgin, C.E.; Corlett, G.K.; Good, S.; McLaren, A.; Rayner, N.; Morak-Bozzo, S.; et al. Sea surface temperature datasets for climate applications from Phase 1 of the European Space Agency Climate Change Initiative (SST CCI). Geosci. Data J. 2014, 1, 179-191. [CrossRef]

8. Merchant, C.J.; Embury, O.; Bulgin, C.E.; Block, T.; Corlett, G.K.; Fiedler, E.; Good, S.A.; Mittaz, J.; Rayner, N.A.; Berry, D.; et al. Satellite-based time-series of sea-surface temperature since 1981 for climate applications. Sci. Data 2019, 6. [CrossRef] [PubMed]

9. While, J.; Mao, C.; Martin, M.J.; Roberts-Jones, J.; Sykes, P.A.; Good, S.A.; McLaren, A.J. An operational analysis system for the global diurnal cycle of sea surface temperature: Implementation and validation. Q.J. R. Meteorol. Soc. 2017, 143, 1787-1803. [CrossRef]

10. Lorenc, A.C.; Bell, R.S.; Macpherson, B. The Meteorological Office analysis correction data assimilation scheme. Q. J. R. Meteorol. Soc. 1991, 117, 59-89. [CrossRef]

11. Martin, M.J.; Hines, A.; Bell, M.J. Data assimilation in the FOAM operational short-range ocean forecasting system: A description of the scheme and its impact. Q. J. R. Meteorol. Soc. 2007, 133, 981-995. [CrossRef] 
12. Mogensen, K.; Alonso-Balmaseda, M.; Weaver, A.; Martin, M.; Vidard, A. NEMOVAR: A variational data assimilation system for the NEMO ocean model. ECMWF Newsl. 2009, 120, 17-21. [CrossRef]

13. Madec, G.; Bourdallé-Badie, R.; Bouttier, P.A.; Bricaud, C.; Bruciaferri, D.; Calvert, D.; Chanut, J.; Clementi, E.; Coward, A.; Delrosso, D.; et al. NEMO ocean engine. Notes du Pôle de Modélisation de línstitut Pierre-Simon Laplace (IPSL) 2017. [CrossRef]

14. Waters, J.; Lea, D.J.; Martin, M.J.; Mirouze, I.; Weaver, A.; While, J. Implementing a variational data assimilation system in an operational 1/4 degree global ocean model. Q. J. R. Meteorol. Soc. 2015, 141, 333-349. [CrossRef]

15. Fiedler, E.K.; Martin, M.J.; Roberts-Jones, J. An operational analysis of Lake Surface Water Temperature. Tellus A Dyn. Meteorol. Oceanogr. 2014, 66, 21247. [CrossRef]

16. Roberts-Jones, J.; Bovis, K.; Martin, M.J.; McLaren, A. Estimating background error covariance parameters and assessing their impact in the OSTIA system. Remote Sens. Environ. 2016, 176, 117-138. [CrossRef]

17. Fiedler, E.K.; Mao, C.; Good, S.A.; Waters, J.; Martin, M.J. Improvements to feature resolution in the OSTIA sea surface temperature analysis using the NEMOVAR assimilation scheme. Q. J. R. Meteorol. Soc. 2019, 145, 3609-3625. [CrossRef]

18. GHRSST Science Team. The Recommended GHRSST Data Specification (GDS) 2.0, Document Revision 4 (2010); GHRSST International Project Office: Leicester, UK, 2011.

19. Wentz, F.; Meissner, T.; Gentemann, C.; Hilburn, K.; Scott, J. Remote Sensing Systems GCOM-W1 AMSR2 (Daily) Environmental Suite on 0.25 deg grid, Version 8a. Remote Sensing Systems, Santa Rosa, CA. Available online: www.remss.com/missions/amsr (accessed on 30 December 2019).

20. REMSS. Remote Sensing Systems GHRSST Level 2P Global Subskin Sea Surface Temperature version 8a from the Advanced Microwave Scanning Radiometer 2 on the GCOM-W satellite. Ver. 8a. PO.DAAC, CA, USA. Available online: https:/ / doi.org/10.5067/GHAM2-2PR8A (accessed on 30 December 2019).

21. Petrenko, B.; Ignatov, A.; Kihai, Y.; Stroup, J.; Dash, P. Evaluation and selection of SST regression algorithms for JPSS VIIRS. J. Geophys. Res. Atmos. 2014, 119, 4580-4599. [CrossRef]

22. NOAA OSPO. Office of Satellite arnd Product Operations GHRSST Level 3U OSPO dataset v2.61 from VIIRS on NOAA-20 Satellite (GDS v2). Ver. 2.61. PO.DAAC, CA, USA. Available online: https: / doi.org/10.5067/ GHV20-3UO61 (accessed on 30 December 2019).

23. Donlon, C.J.; Nightingale, T.J.; Sheasby, T.; Turner, J.; Robinson, I.S.; Emergy, W.J. Implications of the oceanic thermal skin temperature deviation at high wind speed. Geophys. Res. Lett. 1999, 26, 2505-2508. [CrossRef]

24. Donlon, C.J.; Minnett, P.J.; Gentemann, C.; Nightingale, T.J.; Barton, I.J.; Ward, B.; Murray, M.J. Toward Improved Validation of Satellite Sea Surface Skin Temperature Measurements for Climate Research. J. Clim. 2002, 15, 353-369. [CrossRef]

25. Lorenc, A.C.; Hammon, O. Objective quality control of observations using Bayesian methods. Theory, and a practical implementation. Q. J. R. Meteorol. Soc. 1988, 114, 515-543. [CrossRef]

26. Ingleby, B.; Huddleston, M. Quality control of ocean temperature and salinity profiles - Historical and real-time data. J. Mar. Syst. 2007, 65, 158-175. [CrossRef]

27. Storkey, D.; Blaker, A.T.; Mathiot, P.; Megann, A.; Aksenov, Y.; Blockley, E.W.; Calvert, D.; Graham, T.; Hewitt, H.T.; Hyder, P.; et al. UK Global Ocean GO6 and GO7: A traceable hierarchy of model resolutions. Geosci. Model Dev. 2018, 11, 3187-3213. [CrossRef]

28. Steele, M.; Morley, R.; Ermold, W. PHC: A Global Ocean Hydrography with a High-Quality Arctic Ocean. J. Clim. 2001, 14, 2079-2087. [CrossRef]

29. Fofonoff, N.; Millard, R., Jr. Algorithms for the computation of fundamental properties of seawater. In UNESCO Technical Papers in Marine Sciences 44; UNESCO: Paris, France, 1983.

30. Mirouze, I.; Blockley, E.W.; Lea, D.J.; Martin, M.J.; Bell, M.J. A multiple length scale correlation operator for ocean data assimilation. Tellus A Dyn. Meteorol. Oceanogr. 2016, 68, 29744. [CrossRef]

31. Casey, K.S.; Brandon, T.B.; Cornillon, P.; Evans, R. The Past, Present, and Future of the AVHRR Pathfinder SST Program. In Oceanography from Space: Revisited; Barale, V., Gower, J., Alberotanza, L., Eds.; Springer: Dordrecht, The Netherlands, 2010; pp. 273-287._16. [CrossRef]

32. Argo Float Data and Metadata from Global Data Assembly Centre (Argo GDAC); SEANOE: Paris, France, 2020. [CrossRef] 
33. Good, S.A.; Martin, M.J.; Rayner, N.A. EN4: Quality controlled ocean temperature and salinity profiles and monthly objective analyses with uncertainty estimates. J. Geophys. Res. Ocean. 2013, 118, 6704-6716. [CrossRef]

34. Fiedler, E.K.; McLaren, A.; Banzon, V.; Brasnett, B.; Ishizaki, S.; Kennedy, J.; Rayner, N.; Roberts-Jones, J.; Corlett, G.; Merchant, C.J.; et al. Intercomparison of long-term sea surface temperature analyses using the GHRSST Multi-Product Ensemble (GMPE) system. Remote Sens. Environ. 2019, 222, 18-33. [CrossRef]

35. Dash, P.; Ignatov, A.; Kihai, Y.; Sapper, J. The SST Quality Monitor (SQUAM). J. Atmos. Ocean. Technol. 2010, 27, 1899-1917. [CrossRef]

36. Dash, P.; Ignatov, A.; Martin, M.; Donlon, C.; Brasnett, B.; Reynolds, R.W.; Banzon, V.; Beggs, H.; Cayula, J.F.; Chao, Y.; et al. Group for High Resolution Sea Surface Temperature (GHRSST) analysis fields inter-comparisons-Part 2: Near real time web-based level 4 SST Quality Monitor (L4-SQUAM). Deep. Sea Res. Part II Top. Stud. Oceanogr. 2012, 77-80, 31-43. [CrossRef]

37. Martin, M.; Dash, P.; Ignatov, A.; Banzon, V.; Beggs, H.; Brasnett, B.; Cayula, J.F.; Cummings, J.; Donlon, C.; Gentemann, C.; et al. Group for High Resolution Sea Surface temperature (GHRSST) analysis fields inter-comparisons. Part 1: A GHRSST multi-product ensemble (GMPE). Deep. Sea Res. Part II Top. Stud. Oceanogr. 2012, 77-80, 21-30. [CrossRef]

(C) 2020 by the authors. Licensee MDPI, Basel, Switzerland. This article is an open access article distributed under the terms and conditions of the Creative Commons Attribution (CC BY) license (http:/ / creativecommons.org/licenses/by/4.0/). 